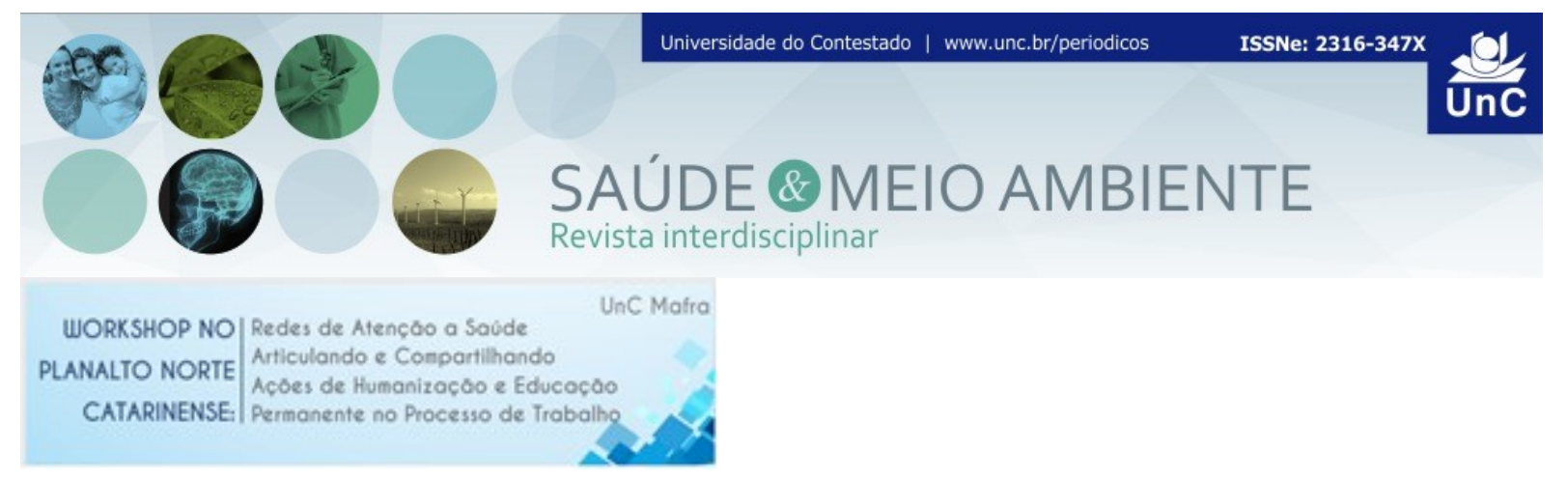

\title{
ESTRATÉGIA SAÚDE DA ALEGRIA: HUMANIZAÇÃO E ALEGRIA NO CUIDADO DOMICILIAR NA ESF EM TRÊS BARRAS/SC
}

\author{
Cristiane Aparecida Hoffmann Lechinheski ${ }^{1}$
}

\section{RESUMO}

INTRODUÇÃO: O município de Três Barras conta com 8 (oito) equipes da Estratégia Saúde da Família (ESF), 100\% de cobertura da população, um Núcleo de Apoio a Saúde da Família (NASF), um Centro de Atenção Psicossocial (CAPS), um Hospital Geral e um Pronto Atendimento. Dentre as equipes da ESF do Município a denominada Equipe 006 da Unidade Básica de Saúde Ailton Mendes, situada no bairro São Cristóvão, que é composta por um médico, uma enfermeira, duas técnicas de enfermagem, cinco Agentes Comunitárias de Saúde, uma recepcionista, uma auxiliar de serviços gerais. A ESF é um modelo assistencial de atenção básica, criado pelo Ministério da Saúde em 1994, que se fundamenta no trabalho de equipes multiprofissionais, realizado a partir do conhecimento da realidade local e das necessidades de sua população. Dentro da estratégia, a família é o objeto da atenção, estudando-se, inclusive in loco, o ambiente em que ela vive (MACHADO et al., 2007). A população da área tem um número bastante expressivo de pessoas idosas (acima de 60 anos), cadeirantes e acamados, pessoas com carência afetiva e de baixo poder aquisitivo, em sua maioria. Observando esse contexto e baseado no projeto Doutores da Alegria, o qual é uma organização da sociedade civil sem fins lucrativos que utiliza a arte do palhaço para intervir junto a crianças, adolescentes e outros públicos em situação de vulnerabilidade e risco social em hospitais públicos (OLIVEIRA; OLIVEIRA, 2008), institui-se o projeto Estratégia Saúde da Alegria, humanizando o atendimento domiciliar, levando solidariedade, humor, carinho, e o lirismo da arte do palhaço para idosos, pessoas com dificuldades de locomoção, pacientes acamados, cadeirantes, deficientes visuais, entre outros, os quais permanecem a maior ou quase todo tempo em seus leitos ou em suas residências, dia após dia, sem muito contato com a sociedade. OBJETIVO: Intensificar a proximidade entre a equipe da ESF e as famílias atendidas pela UBS Ailton Mendes, levando alegria, motivação e um atendimento humanizado em seus domicílios. MATERIAL E MÉTODOS: Na data programada para a execução do Projeto Estratégia Saúde da Alegria, a equipe realiza em média 10 (dez) visitas domiciliares, nas quais são priorizados os acamados e idosos e os demais pacientes conforme necessidade. A ESF prevê a utilização da assistência domiciliar à saúde, em especial, a visita domiciliar, como forma de instrumentalizar os profissionais para sua inserção e o conhecimento da realidade de vida da população, bem como o

\footnotetext{
${ }^{1}$ Enfermeira Pós-graduada em Estratégia Saúde da Família pela Universidade Federal de SC/UFSC. E-mail: postoaltonmendes006@gmail.com
} 
estabelecimento de vínculos com a mesma; visando atender as diferentes necessidades de saúde das pessoas, preocupando-se com a infraestrutura existente nas comunidades e o atendimento à saúde das famílias (GIACOMOZZI; LACERDA, 2006). As visitas são efetuadas nos dias que antecedem datas comemorativas, como: Dia Mundial da Saúde, Páscoa, Dia das Mães, Dia dos Pais, Dia do Aniversário, Natal, entre outras. A equipe comemora com os pacientes, datas que para muitos deles ficam por vezes esquecidas. Todos os profissionais da equipe saem caminhando pelas ruas ou vão com algum meio de locomoção que acomode a todos. Por onde passam toda a população sente-se homenageada, a diversão é garantida e a alegria contagia a todos. Os integrantes caracterizam-se com perucas, óculos, pintura facial e a figura do palhaço torna-se fundamental, pois ela caracteriza o riso e a alegria. Quando a equipe chega a seu destino a música torna-se essencial para alegrar ainda mais o ambiente, os procedimentos técnicos são realizados pela enfermagem e uma lembrança é deixada como motivação para os enfermos. As lembranças são confeccionadas ou doadas pela equipe e pela comunidade que reside na área, conforme a data comemorativa. A equipe da Estratégia Saúde da Alegria transmite aos pacientes a sua importância para a sociedade, para os profissionais de saúde, familiares e amigos. Demonstram que sentimentos como afeto, carinho e reconhecimento podem ser transmitidos em um simples gesto, um abraço apertado e verdadeiro, palavras positivas, de confiança e de fé fazem a diferença e são suficientes para fazer uma pessoa feliz. Os encontros dos profissionais com os pacientes podem ser momentâneos, mas tornam-se marcantes e inesquecíveis na vida destas pessoas. Assim, a ESF 006 promove o fortalecimento dos vínculos entre os profissionais e usuários dos serviços de saúde. RESULTADOS: Com o projeto busca-se levar um atendimento humanizado, instaurando o bem-estar físico, psíquico e social dos pacientes e seus familiares. Promovendo qualidade de vida aos usuários e a satisfação dos profissionais em atendê-los de forma diferenciada, intensificando assim o fortalecimento dos vínculos entre equipe, pacientes e familiares. O projeto tornou-se uma ferramenta importante na humanização dos atendimentos realizados pela ESF, pois nas visitas periódicas programadas, nota-se que os profissionais são acolhidos de forma carinhosa e os pacientes demonstram confiança estando em sua presença. A humanização precisa ser sentida e percebida pelos pacientes, familiares e equipe de saúde, sendo que cada processo de humanização é único e singular, dependendo de cada profissional, de cada equipe e de cada instituição (CASATE; CORRÊA, 2005). A capacidade criativa e os talentos escondidos em cada um dos participantes do projeto proporcionaram mudanças na maneira convencional de se promover saúde, pois os profissionais são envolvidos pela emoção e com isso unem-se com o único propósito de fazer o bem. Os relatos dos pacientes e familiares é o que nos impulsiona a continuar. CONCLUSÃO: Pode-se perceber, por relatos dos pacientes, familiares e dos profissionais, que o projeto superou expectativas, cada visita realizada se torna única, pois um olhar transmite emoções que não podem ser expressadas através de palavras. Conclui-se que a maneira lúdica de se promover saúde acarreta inúmeros benefícios aos pacientes atendidos, pois transmite alegria, encorajamento para enfrentar sua enfermidade, comoção de familiares e amigos em ver a felicidade no rosto de seu ente querido e que um simples gesto desperta o sentimento de gratidão e a esperança de dias melhores. Verificou-se que muitos pacientes que foram visitados pelo projeto são pessoas que sofrem de carência afetiva, muitas delas esquecidas por seus familiares, outras que se encontram 
sozinhas, dependendo da solidariedade humana. Há depoimentos de famílias que atualmente não fazem parte da área 006, por não estarem mais residindo no Município, que sentem falta do atendimento diferenciado e humanizado que o projeto proporciona. A equipe da Estratégia Saúde da Alegria está motivada a manter sua trajetória, pois acredita-se que, mediante a continuidade das ações, novas estratégias e idéias serão implementadas, produzindo novas formas de fazer ESF com humanização.

Palavras-chave: Humanização. Alegria. Cuidado. Motivação.

\section{REFERÊNCIAS}

CASATE, J. C.; CORRÊA, A. K. Humanização do atendimento em saúde: conhecimento veiculado na literatura brasileira de enfermagem. Rev. Latino-Am. Enfermagem, Ribeirão Preto, v. 13, n. 1, p. 105-111, jan./fev. 2005.

GIACOMOZZI, C. M.; LACERDA, M. R. A prática da assistência domiciliar. Texto contexto - enferm., Florianópolis, v. 15, n. 4, p. 645-653, Dec. 2006.

MACHADO, M. F. A. S. et al. Integralidade, formação de saúde, educação em saúde e as propostas do SUS: uma revisão conceitual. Ciências Saúde Coletiva, Rio de Janeiro, v. 12, n. 2, p. 335-342, Apr. 2007.

OLIVEIRA, R. R.; OLIVEIRA, I. C. S. Temática sobre os Doutores da Alegria na unidade de internação. Escola Anna Nery Revista de Enfermagem, v. 12, n. 2, p. 230-236, jun., 2008.

Resumo recebido em: 08/12/2017

Resumo aprovado em: 17/12/2017

Resumo publicado em: 20/12/2017 